26. Юрицына Н.А. Растительность засоленных почв Юго-Востока Европы и сопредельных территорий. Тольятти: Кассандра, 2014. 164 с.

27. Горбушина Т.В., Новикова Л.А. Исследования Б.А. Келлера на территории Пензенской области (К 140-летию со дня рождения) // Экология и география растений и сообществ Среднего Поволжья: сб. всерос. конф. (г. Тольятти, 3-5 октября 2014 г.) / под ред. С.А. Сенатора, С.В. Саксонова, Г.С. Розенберга. Тольятти: Кассандра, 2014. С. 508-516.

28. Пчелинцева Т.И. Проблемы сохранения ценных участков растительности в Малосердобинском районе (Пензенская область) // Природное наследие России: сб. науч. ст. междунар. науч. конф., посв. 100-летию национального заповедного дела и Году экологии в России (г. Пенза, 23-25 мая 2017 г.). Пенза: Изд-во ПГУ, 2017. С. 317-318.

29. Vasjukov V.M., Novikova L.A., Pankina D.V., Shcherbakov M.G. Artemisia nitrosa Stechm. // Willdenowia. 2015. Vol. 45. P. 451.

30. Вяль Ю.А., Новикова Л.А., Карпова Г.А., Лойко Н.Г. Особенности генезиса гипноносных луговых почв в условиях Пензенской области // Нива Поволжья. 2013. Вып. 2 (27). С. 21-26.

31. Вяль Ю.А., Новикова Л.А., Лойко Н.Г., Мазей Н.Г., Карпова Г.А. Засоленные луговые почвы как компонент транссупераквальных ландшафтов лесостепи // Лесостепь Восточной Европы: структура, динамика и охрана: сб. ст. междунар. науч. конф., посв. 140-летию со дня рождения И.И. Спрыгина (г. Пенза, 10-13 июня 2013 г.). Пенза: Изд-во Пензенского гос. ун-та, 2013. С. 364-366.

32. Новикова Л.А., Вяль Ю.А., Леонова Н.А., Панькина Д.В. Геоботаническая характеристика «Ольшанского солонца» в Пензенской области // Нива Поволжья. 2014. Вып. 1 (30). С. 49-56.

Работа выполнена в рамках госзадания Института экологии Волжского бассейна РАН, тема (проект) № 0128-2014-0002 «Оценка современного биоразнообразия и прогноз его изменения для экосистем Волжского бассейна в условиях их природной и антропогенной трансформации" (направление 52 «Биологическое разнообразие»).

\title{
THE STUDY OF HALOPHYTIC VEGETATION OF THE PENZA REGION AND ITS PROTECTION
} (C) 2019

\author{
Novikova Lyubov Aleksandrovna, doctor of biological sciences, \\ professor of General Biology and Biochemistry Department \\ Penza State University (Penza, Russian Federation) \\ Vasjukov Vladimir Mikhailovich, candidate of biological sciences, \\ researcher of Phytodiversity Problems Laboratory \\ Institute of Ecology of the Volga River Basin of Russian Academy of Sciences \\ (Togliatti, Samara Region, Russian Federation) \\ Gorbushina Tatiana Viktorovna, candidate of agricultural sciences, researcher \\ State Natural Reserve «Privolzhskaya Forest-Steppe» (Penza, Russian Federation)
}

Abstract. 15 sites with saline soils have been identified and described in the Penza Region. Only 2 of them have a status of a nature sanctuary. They are the «Solontsovaya Steppe» in the Luninsky District and the «Danilovskaya Solontsovaya Polyana» in the Maloserdobinsky District. The other 13 sites are proposed to be included in the existing system of specially protected natural territories of the Penza Region as nature sanctuaries. They are «Zhmakinsky Solonetz», «Kaysarovsky Solonetz»(Kolyshley District); Litvinovsky Solonetz (Lopatinsky District); «Chunak Solontsovaya Glade», «Korzovaya Hollow» (Maloserdobinsky District); «Kellerovsky Solonetz», «Mansurovsky Solonetz», «Karnovarsky Solonetz» (Neverkinsky District); «Olshansky Solonetz», «Andreevsky Solonetz», «Vasilyevsky Solonetz» (Penza District); «Serdobsky Solonetz», «Krasny Solonetz» (Serdobsky District). We provide the following data for each site. This is the history of discovery (dates, researches), location, belonging to the basins of large rivers, approximate area, information about economic use in the past and the degree of anthropogenic disturbances, the characteristics of the relief and soil. The main attention is paid to the description of the nature of the distribution of halophilic vegetation, depending on the degree of salinity and soil moisture. Data on the steppes vegetation, meadows and swamps found in the described sites are also given. Dominant and rare species of vascular plants (in The Red Book of the Penza Region) are listed.

Keywords: halophytic vegetation; halophytes; Penza Region; specially protected natural areas; nature sanctuary; Red book; rare species; halophytic steppes; saline lowland marshes; halophytic meadows; saline; saline areas; protection of unique species and communities.

\section{ГРАНИЦЫ ВСХОЖЕСТИ СЕМЯН ФИТОМЕЛИОРАНТОВ В ПРИСУТСТВИИ ТОКСИЧНЫХ КОНЦЕНТРАЦИЙ ТЯЖЕЛЫХ МЕТАЛЛОВ}

(C) 2019

Ознобихина Анастасия Олеговна, аспирант кафедры техносферной безопасности Тюменский индустриальньй университет (2. Тюмень, Российская Федерация)

Аннотация. Цель исследования заключается в проведении биологического тестирования на начальных стадиях жизнеспособности растительных объектов в модельных условиях загрязнения тяжелыми металлами. 
В статье представлены результаты лабораторных опытов по оценке влияния различных концентраций солей тяжелых металлов на жизнеспособность семян донника желтого и люцерны посевной. Проведенными экспериментальными исследованиями установлена прямая зависимость уменьшения показателей энергии прорастания и лабораторной всхожести семян при повышении концентрации солей фитотоксикантов, определены критическая (пороговая) концентрация изучаемых элементов и содержание металла, при котором процессы роста и развития семян сохраняются. Оптимальной для всхожести семян донника является концентрация 0,01\% по кадмию, цинку, свинцу и меди, где всхожесть составила 80\%, 74\%, 69\% и 64\% соответственно. Для семян люцерны высокие показатели всхожести отмечены в $0,01 \%$ загрязнении свинцом, цинком, кадмием и медью $-82 \%, 80 \%, 77 \%$ и 76\% соответственно, а также в $0,1 \%$ растворе соли свинца, меди и цинка зафиксировано $75 \%, 74 \%$ и $72 \%$ проростков. Цинк в концентрации $0,01 \%$ на начальных этапах всхожести семян фитомелиорантов оказывал стимулирование энергии прорастания. Отмечена тенденция устойчивости к загрязнению свинцом, цинком и медью у всходов люцерны посевной, к загрязнению кадмием наибольшую устойчивость проявил донник желтый. Определение границ всхожести семян бобовых растений в присутствии токсичных агентов позволит проводить научные разработки по биологической рекультивации загрязненных почв и может быть использовано на техногенно-нарушенных территориях.

Ключевые слова: тяжелые металлы; почвенное загрязнение; поллютанты; фитомелиоранты; семена донника; семена люцерны; энергия прорастания; лабораторная всхожесть; фитотоксичность; токсичная концентрация; пороговая концентрация; оптимальная концентрация; цинк; медь; кадмий; свинец; границы устойчивости.

\section{Введение}

Загрязнение природной среды сегодня является острой экологической проблемой. В последние десятилетия в связи с быстрым развитием промышленности во всем мире наблюдается значительное возрастание содержания тяжелых металлов в окружающей среде и продуктах питания [1-5].

В результате хозяйственной деятельности человека тяжелые металлы поступают в окружающую среду в количествах, сопоставимых с количествами металлов, участвующих в природных процессах круговорота, что приводит к ее загрязнению. Земли, включенные в сельскохозяйственный оборот, с каждым годом становятся все более истощенными и экологически уязвимыми [6-11].

Проблема деградации техногенно-нарушенных почв вследствие загрязнения тяжелыми металлами является особенно актуальной. Для устойчивого развития аграрного производства необходимы биометоды и биотехнологии, которые без вреда для растительного и животного мира, в том числе для человека являются безопасными, способствуют повышению качества и количества готовой продукции [12-15].

Возделывание растений-фитомелиорантов, в частности донника желтого и люцерны посевной, способствует очищению почвы, улучшению химических и физических свойств, повышению ее плодородия.

Проведение модельных исследований по влиянию различных доз и видов тяжелых металлов на растительные объекты позволит решить следующие задачи: установить границы разной устойчивости растений и тенденции приспособления к токсикантам, выявить влияние конкретного металла, выяснить летальные дозы, а также концентрации при которых сохраняется жизнеспособность тест-объектов.

Целью исследований явилось изучение возможности жизнеспособности семян фитомелиорантов в модельных условиях загрязнения тяжелыми металлами.

\section{объекты исследований}

В качестве тест-объектов были выбраны семена фитомелиорантов - донника желтого (Melilotus officinalis) и люцерны посевной (Medicago sativa).

\section{Материалы и методика исследований}

Эксперимент проводился в лабораторных условиях, семена проращивали в чашках Петри на слое фильтровальной бумаги, смоченной водным раствором соли тяжелых металлов. В качестве токсиканта использовали растворы нитрата свинца, сульфата меди, нитрата кадмия и сульфата цинка следующих концентраций: $0,01 \% ; 0,1 \% ; 0,3 \% ; 0,5 \% ; 1 \% ; 3 \% ; 5 \%$ и $6 \%$ по каждому металлу в отдельности. В контрольном варианте семена смачивались только дистиллированной водой. Проращивание осуществлялось в соответствии с ГОСТ 12038-84. Семена сельскохозяйственных культур. Методы определения всхожести: энергию прорастания семян определяли на 4-е сутки проращивания; лабораторную всхожесть у семян люцерны - на 7-е сутки, у донника - на 10-е сутки.

\section{Результаты исследований и их обсуждение}

При оценке влияния модельного загрязнения среды на жизнеспособность семян донника желтого и люцерны посевной, представленной на рисунках 1-4, выявлены следующие закономерности: отмечено снижение показателей прорастания семян при повышении концентрации раствора солей свинца, меди, кадмия во всех исследуемых вариантах; наблюдалось некоторое увеличение энергии прорастания семян тестируемых культур при $0,01 \%$ концентрации соли цинка, однако для всхожести семян данная тенденция не характерна и наблюдается ингибирующее действие уже при минимальной концентрации раствора.

Признаки угнетения энергии прорастания семян донника по отношению к контролю (рис. 1) наблюдались уже при минимальной $0,01 \%$ концентрации кадмия, меди и свинца, разница между контрольным вариантом и моделируемым $0,01 \%$ образцом составила $8 \%, 18 \%$ и $63 \%$ соответственно. При загрязнении среды солью цинка в концентрации $0,01 \%$ отмечалось незначительное стимулирование энергии прорастания, что составило 52\% всхожих семян при $49 \%$ в контрольном варианте.

Каждое последующее увеличение концентрации тяжелых металлов приводило к снижению процесса прорастания семян донника. 


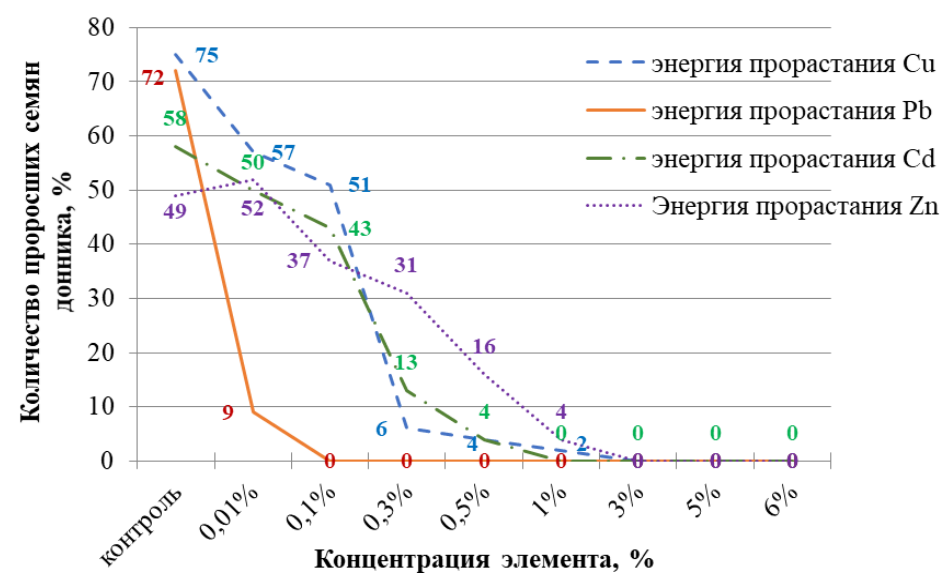

Рисунок 1 - Результаты определения энергии прорастания семян донника желтого в зависимости от концентрации фитотоксиканта, \%

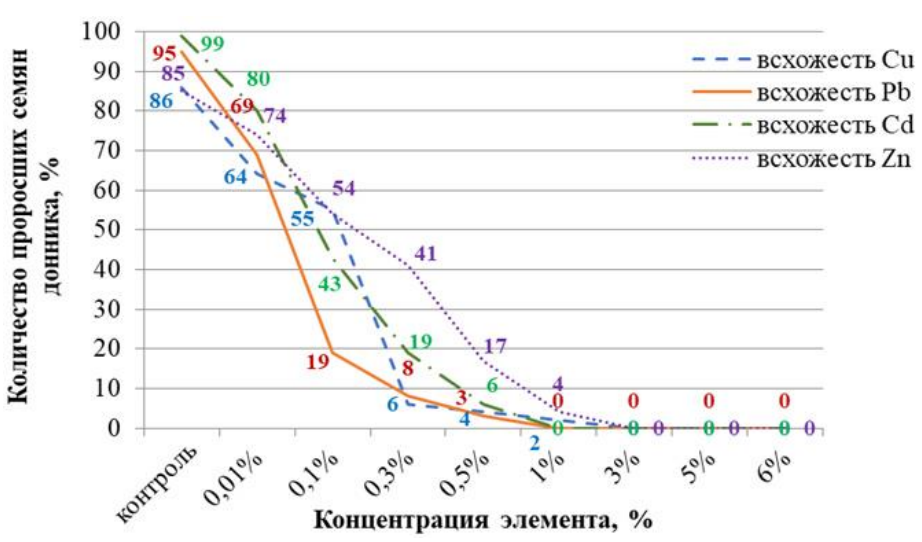

Рисунок 2 - Результаты определения всхожести семян донника желтого в зависимости от концентрации фитотоксиканта, \%

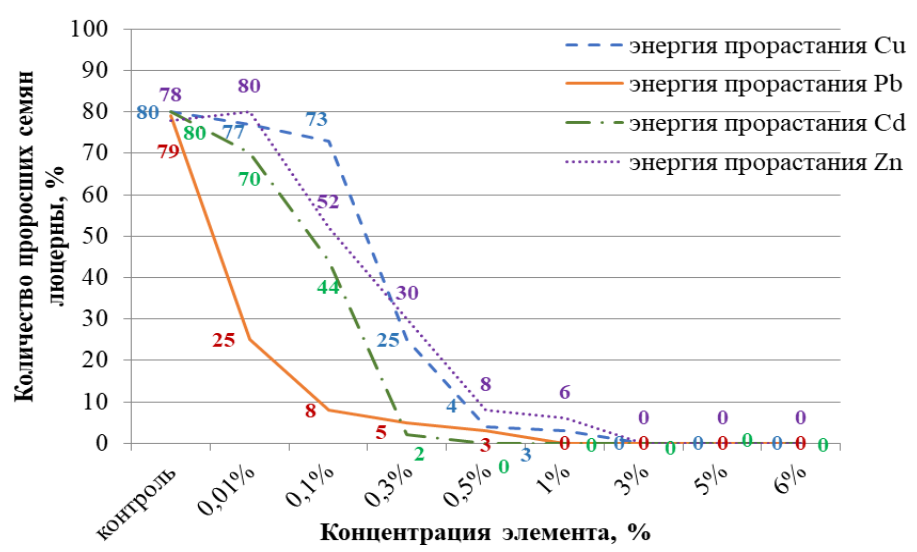

Рисунок 3 - Результаты определения энергии прорастания семян люцерны посевной в зависимости от концентрации фитотоксиканта, \%

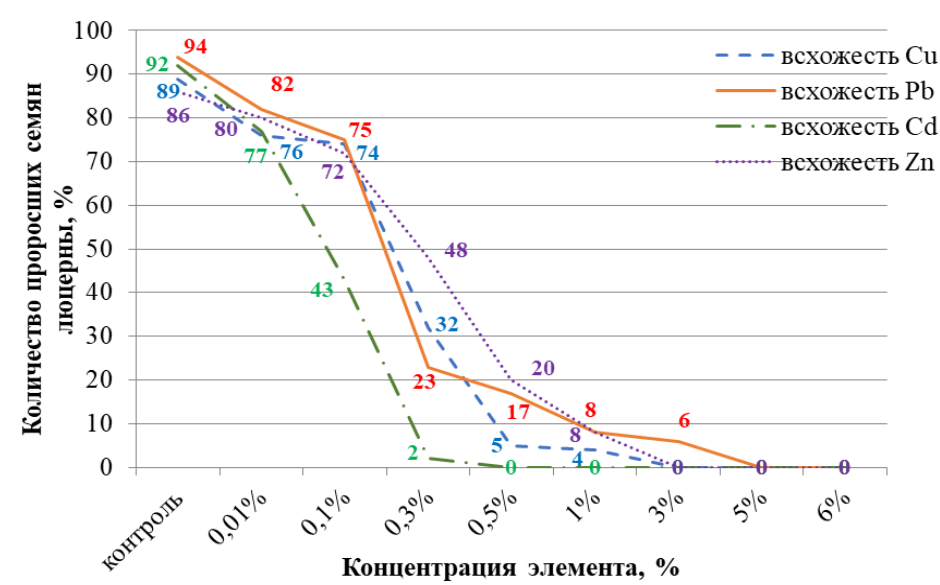

Рисунок 4 - Результаты определения всхожести семян люцерны в зависимости от концентрации фитотоксиканта, \% 
При определении всхожести семян донника (рис. 2) можно отметить следующее: с увеличением концентрации раствора солей тяжелых металлов от $0,01 \% \rightarrow 0,1 \% \rightarrow 0,3 \% \rightarrow 0,5 \% \rightarrow 1 \%$ показатели всхожести значительно снижаются в отличие от контрольного варианта, наименьшее ингибирование прорастания наблюдалось по цинку 74\% проросших семян - в варианте $0,01 \%$ раствора соли; $54 \%$ семян - при $0,1 \%$ концентрации; $41 \%$ семян - при $0,3 \%$ содержании; $17 \%$ семян - в среде $0,5 \%$ раствора соли и 4\% семян - при 1\% концентрации элемента. При загрязнении среды медью лабораторная всхожесть семян снизилась на $22-31 \%$ в $0,01 \%$ и $0,1 \%$ растворе соли соответственно, далее с повышением концентрации наблюдалось резкое сокращение количества проростков: $6 \%$ проросших семян в $0,3 \%$ концентрации раствора, $4 \%$ семян - в $0,5 \%$ концентрации и $2 \%$ семян - в $1 \%$ концентрации. В модельном варианте с кадмием и свинцом критической для прорастания стала концентрация $0,5 \%$ раствора соли, при которой сохраняют жизнеспособность $6 \%$ и $3 \%$ всхожих семян соответственно. В концентрациях $0,01 \%, 0,1 \%$ и $0,3 \%$ кадмия отклонения от контроля составили 1,2-2,35,2 раза; по свинцу 1,2-5-11,9 раз соответственно.

Наиболее сильное угнетение энергии прорастания и всхожести семян донника характерно при загрязнении среды солью свинца.

Угнетающее действие элементов на процесс прорастания семян донника в порядке убывания можно выразить в следующей последовательности: свинец $>$ кадмий $>$ медь $>$ цинк.

По результатам исследований влияния солей тяжелых металлов на процессы прорастания семян люцерны (рис. 3) отмечено ингибирование энергии прорастания: при 0,01\% концентрации меди количество проростков снизилось на $3 \%$; в варианте с кадмием - на $10 \%$; при загрязнении свинцом - на 54\%; цинк в данной концентрации стимулировал рост семян на $2 \%$. С увеличением концентрации раствора солей токсикантов наблюдалось снижение энергии прорастания семян.

Лабораторная всхожесть семян (рис. 4) была ниже контроля во всех моделируемых вариантах. Снижение всхожести семян люцерны было наиболее сильным в варианте с кадмием, где проросло наименьшее количество семян 77\% проростков - в $0,01 \%$ концентрации раствора, $43 \%$ семян - в $0,1 \%$ содержании и $2 \%$ семян - в $0,3 \%$ дозе металла, которая стала критической.

В модельном образце с медью и цинком критической установлена концентрация $1 \%$ раствора соли, где жизнеспособность сохранили 4\% и $8 \%$ семян соответственно; для свинца порогом выживаемости семян стало $3 \%$ содержание элемента, в котором отмечено 6\% проростков.

Ингибирование прорастания семян люцерны тяжелыми металлами в порядке убывания можно выразить в следующей закономерности: кадмий $>$ медь $>$ цинк > свинец.

Семена донника и люцерны по-разному реагируют на токсичность элементов и их концентраций. В целом донник желтый наиболее чувствителен к загрязненной среде, чем люцерна посевная: снижение показателей всхожести зафиксировано в опыте с медью, свинцом и цинком. Для донника устойчивость в сравнении с люцерной прослеживалась лишь по отношению к кадмию: $6 \%$ всхожих семян в $0,5 \%$ концентрации, которая для люцерны стала летальной и $19 \%$ проростков донника в соотношении с $2 \%$ люцерны в 0,3\% загрязнении среды. Напротив, для люцерны характерны благоприятные показатели всхожести семян к свинцовому загрязнению, даже при высоких концентрациях: $6 \%$ всхожих семян в 3\% загрязнении среды, что по доннику составило лишь $3 \%$ в $0,5 \%$ растворе соли.

Полное ингибирование всхожести наблюдается при следующих концентрациях тяжелых металлов: для семян донника - $1 \%$ и выше соли свинца и кадмия, 3\% и выше соли меди и цинка; для семян люцерны 0,5\% и выше - соли кадмия, $3 \%$ и выше - соли меди и цинка; 5\% и выше соли свинца.

\section{Выводы}

Процесс жизнеспособности семян фитомелиорантов является довольно устойчивым к действию тяжелых металлов при 0,01\% концентрации токсикантов, где жизнеспособность проростков составляла 64$80 \%$ всхожих семян донника желтого и 76-82\% люцерны посевной. Высокие показатели всхожести семян люцерны также отмечены в $0,1 \%$ загрязнении цинком, медью и свинцом - 72\%, - 74\%, - 75\% всхожих семян соответственно.

Концентрация цинка $0,01 \%$ при непродолжительном действии оказывала стимулирование энергии прорастания семян донника на $3 \%$ выше контроля, люцерны - на $2 \%$.

В сравнении культуры неодинаково реагируют на загрязнение тяжелыми металлами: люцерна посевная проявила устойчивость к загрязнению свинцом, цинком и медью, донник наиболее устойчив к загрязнению кадмием.

Знание границ устойчивости фитомелиорантов, оптимальных и критических доз тяжелых металлов позволит проводить научные разработки по биологической рекультивации загрязненных почв и может быть использовано на техногенно-нарушенных территориях.

\section{Список литературы:}

1. Ознобихина А.О., Скипин Л.Н., Котченко С.Г., Гаевая Е.В., Захарова Е.В. Особенности накопления тяжелых металлов в почвах северной лесостепи районов Тюменской области // Вестник КрасГАУ. 2018. № 5. С. 252-257.

2. Гаевая Е.В., Захарова Е.В., Скипин Л.Н. Биогеохимия элементов в системе почва - растение животное в условиях юга Тюменской области // Вестник КрасГАУ. 2013. № 11. С. 149-153.

3. Наплекова Н.Н., Степанова М.Д. Биоиндикация загрязнения почв свинцом и кадмием по микробным ценозам. Новосибирск, 2000. 124 с.

4. Ильин В.Б. Тяжелые металлы в системе почва растение. Новосибирск: Наука, Сибирское отделение, 1991. $151 \mathrm{c.}$

5. Кузнецов А.Е., Градова Н.Б., Лушников С.В., Энгельхарт М. Прикладная экобиотехнология: учеб. пособие для студентов. В 2 т. 2-е изд. (электронное). М.: Бином. Лаб. знаний, 2012.

6. Боме Н.А., Белозерова А.А. Основы биотехнологии растений: учеб. пособие. Тюмень: Изд-во ТюмГУ, 2007. 92 с. 
7. Oznobihina A.O., Gayevaya E.V. Heavy Metals in Soil\&Plant System Under Conditions of the South of Tyumen Region // IOP Conference Series: Materials Science and Engineering (MSE) International Conference on Construction, Architecture and Technosphere Safety, ICCATS 2017. Vol. 262. Chelyabinsk: South Ural State University, 2017. P. 012170.

8. Савич В.И., Седых В.А., Никиточкин Д.Н., Сердюкова А.В., Шестаков А.К., Саидов Е.И. Агроэкологическая оценка состояния почв в системе почва - растение. М.: Изд-во ВНИИА, 2012. 360 с.

9. Барсегян А.Г., Гендугов В.М., Глазунов Г.П. и др. Экологическое нормирование и управление качеством почв и земель. М.: НИА-Природа, 2013. 373 с.

10. Глазовская М.А. Геохимия природных и техногенных ландшафтов. М.: Высшая школа, 1988. 328 с.
11. Сысо А.И. Закономерности распределения химических элементов в почвообразующих породах и почвах Западной Сибири. Новосибирск: Изд-во СО PAH, 2007. $277 \mathrm{c}$.

12. Муха В.Д., Картамышев Н.И., Муха Д.В. Агропочвоведение. М.: КолосС, 2004. С. 480-485.

13. Черников В.А., Грингоф И.Г., Емцев В.Т. Агроэкология. Методология, технология, экономика. М.: КолосС, 2004. 400 c.

14. Витол И.С. Экологические проблемы производства и потребления пищевых продуктов: учебное пособие. М.: Издательский комплекс МГУПП, 2000. $93 \mathrm{c}$.

15. Давыдова С.Л., Тагасов В.И. Тяжелые металлы как супертоксиканты 21 века. М.: Изд-во РУДН, 2002. $140 \mathrm{c}$.

\title{
LIMITS OF SEED GERMINATION OF PHYTOMELIORANTS UNDER CONDITIONS OF HEAVY METALS TOXIC CONCENTRATIONS
}

(C) 2019

Oznobihina Anastasia Olegovna, postgraduate student of Technosphere Safety Department Tyumen Industrial University (Tyumen, Russian Federation)

Abstract. The aim of the study is to conduct biological testing at the initial stages of plant objects viability in the model conditions of heavy metal pollution. The paper presents the results of laboratory experiments to assess the impact of different concentrations of heavy metal salts on the viability of yellow melilot and great trefoil seeds. In the course of the conducted experimental studies the author has been established a direct dependence of the decrease in the indices of germination energy and laboratory germination of seeds with an increase in the concentration of phytotoxicant salts, determined the critical (threshold) concentration of the studied elements and the metal content, in which the processes of growth and development of seeds remain. The concentration of $0,01 \%$ cadmium, zinc, lead and copper was optimal for germination of melilot seeds, where germination was equal to 80\%, 74\%, 69\% and 64\%, respectively. For great trefoil seeds, high germination rates were noted in case of $0,01 \%$ contamination with lead, zinc, cadmium and copper $-82 \%, 80 \%, 77 \%$ and $76 \%$, respectively, and in $0,1 \%$ salt solution of lead, copper and zinc there were recorded $75 \%, 74 \%$ and $72 \%$ of seedlings. Zinc in the concentration of $0,01 \%$ at the initial stages of germination of phytomeliorant seeds stimulated germination energy. The tendency of resistance to pollution by lead, zinc and copper was observed at sprouts of a great trefoil, and to pollution by cadmium the greatest resistance was shown by a melilot yellow. Defining the limits of the leguminous plant seeds germination in the presence of a toxic agent will allow research and development in respect of biological restoration of contaminated soils and can be used in technologically disturbed lands.

Keywords: heavy metals; soil pollution; pollutants; phytomeliorants; clover seeds; alfalfa seeds; germination energy; laboratory germination; phytotoxicity; toxic concentration; threshold concentration; optimal concentration; zinc; copper; cadmium; lead; stability limits.

\section{УДК 595.774.2}

DOI 10.24411/2309-4370-2019-11114

Статья поступила в редакцию 11.10 .2018

\section{О ПОЛОВОЙ СТРУКТУРЕ ПОПУЛЯЦИИ У МУХ-КРОВОСОСОК (DIPTERА, НIPPOВОSCIDAE) РОДА ОRNITHОМYА LATREILLE, 1802 В ЦЕНТРАЛЬНОМ РЕГИОНЕ И НА СЕВЕРЕ РОССИИ}

(C) 2019

\author{
Павлов Александр Владимирович, учитель биологии
}

Муромиевская средняя общеобразовательная школа

(n. Муромиево, Судогодский район, Владимирская область, Российская Федераичя)

Быков Юрий Александрович, научный сотрудник отдела науки и экопросвещения

Наџиональный парк «Мещера» (2. Гусь-Хрустальный, Владимирская область, Российская Федерация)

Матюхин Александр Владимирович, кандидат биологических наук,

научный сотрудник Центра кольцевания птиц

Институт проблем экологии и эволющчи им. А.Н. Северцуова РАН (г. Москва, Российская Федерация)

Аннотация. В данной статье рассматривается соотношение полов в популяциях у мух-кровососок рода Ornithomya Latreille, находящихся на территории Владимирской и Мурманской областей. В ходе кольцевания птиц с 2014 года нами проводится сбор паразитирующих на них мух-кровососок. Всего за четыре года во Владимирской области нами осмотрено 12515 птиц, с которых снято 94 самки и 17 самцов кровососки Ornithomya avicularia L., 1758, а также 142 самки и 37 самцов Ornithomya fringillina Curtis, 1836. На территории Мурманской области в 2016 и 2017 годах с птиц собрано 465 самок и 91 самец Ornithomya chloropus Bergot, 